\title{
Certainty, Severity, and their Relative Deterrent Effects: Questioning the Implications of the Role of Risk in Criminal Deterrence Policy
}

\begin{abstract}
In the late 60s, Gary Becker incorporated into his formal model of deterrence theory an explicit statement that the theory's components - certainty and severity of punishment-are more or less influential than one another depending on an individual's preference for risk. The certainty of punishment is more influential than the severity of punishment in the decision of whether or not to commit crime if an individual is risk acceptant; if a criminal is risk averse, then the severity of punishment is more important than the certainty of punishment. Many aggregate deterrence studies arrive at estimates that reveal varying effects of the certainty and severity components of deterrence theory, with the certainty of punishment carrying the greater, and many times the only, weight. Leaning on Becker's extension of deterrence theory, empiricists assume that criminals have a preference for risk. Assertions that arrests and convictions are greater deterrent tools imply important worldly consequences because they indicate to governmental authorities where resources should be invested to insure the best deterrent payoff. In this paper, I question both the need to take risk into consideration in aggregate level deterrence studies and the empirical evidence that has been offered in support of attaching greater weight to the certainty of punishment. I show, first, that deterrence theory, from an applied policy standpoint, is encumbered through the explicit consideration of risk preferences. Next, I work through the algebra of the statistical formulations of deterrence models and demonstrate that the greater weight associated with certainty could well be an artifact of the model specification. Finally, I reanalyze data that appear to be consistent with the greater weight for certainty than severity argument and show that the evidence does not support that inference. Potential criminals mentally combine the three deterrence components - regardless of whether they are risk neutral, averse, or acceptant. I conclude by considering what it means to a worldly application of criminal deterrence theory to place equal weight on the certainty and the severity of punishment.
\end{abstract}

In the criminal deterrence literature, three elements, combined, produce an expected cost of punishment: the probability of arrest, the probability of conviction, and the severity of punishment. Either by raising the certainty that a criminal will be punished - through the increased probability of arrest and/or the probability of conviction of those arrested — or by raising the severity of punishment through extended time served in prison, a government should be able to reduce the crime rate in its jurisdiction. So says the theory. The theoretical logic of criminal deterrence is disarmingly simple and, perhaps for that reason, persuasive. It is supposed to reduce crime by setting the expected cost of committing a crime high enough to dissuade potential criminals from choosing to commit illegal acts. In theory, analysis, and practice, however, things are not so simple. 
There is a widely-held notion in the literature that the three deterrence elements have differential effects on the expected cost of punishment. Many existing empirical deterrence studies allow us to draw the inference that the magnitude of the effect of the certainty of punishment, particularly the probability of arrest, is greater than that of the effect of the severity of punishment (Eide, 1994; Witte, 1983). The disagreement regarding the differential roles of the certainty and the severity of punishment divide scholars into three general groups. At one extreme, there are deterrence analysts who would have us believe that the severity of punishment is of little consequence (Eide, 1994; Decker and Kohfeld, 1990; Witte, 1983). In the middle, there are theorists and analysts who tell us that severity is relatively less important than the certainty of punishment (e.g., Becker, 1968; Ehrlich, 1973). At the other extreme, there are those scholars who believe the elements should be equally important (e.g., Chambliss, 1966; Tittle, 1969; Gibbs, 1968; Gray and Martin, 1969; Antunes and Hunt, 1973; Logan, 1972; Grasmick and Bryjak, 1980; Mendes and McDonald, 2001). Among the authors of this last group is Gordon Tullock (1974, p.107), who questions "whether the severity of the sentence or the likelihood that it will be imposed is more important in deterring crime. In my opinion, this is not a very important question. Why should it matter if a criminal faces a one-in-100 probability of being convicted for one year in prison or a one-in-1000 probability of being imprisoned for 10 years?" In both cases, the expected cost for the criminal is precisely the same.

There are three possible explanations in the economics, sociology, psychology, and criminology literatures for why these authors disagree on the deterrent power of each element of deterrence theory. One explanation lies with the magnitude differential of these elements and can be justified on the grounds of an attitudinal, unobservable feature-risk - that Gary Becker (1968) built into deterrence theory for reasons that go back to the beginning of criminology and has gone, for the most part, largely unchallenged. Most empiricists, beginning with Ehrlich (1973) and Sjoquist (1973), have tacitly accepted risk in the statistical models they employ to test deterrence theory. Another explanation might rest with the issue of the potential incorporation of time horizons into their reasoning so that proximity 
or longevity of punishment in time, that is, the celerity of punishment, affects whether certainty or severity has the greater bearing on the expected cost of punishment. Individuals vary as to how they value and discount time. Although scholars may not have been using terms such as discount factors at the time, the celerity or swiftness of punishment goes back to Beccaria and Bentham. One final justification for a source of variability among the deterrence elements are what are called extra-legal consequences associated with criminal behavior. These are often referred to as informal self- and society-imposed sanctions such as shame, embarrassment, and stigma. Individuals differ as to how they regard being arrested, tried, convicted, and/or serving time.

While these different exponential effects may sound inconsequential, the weights issue has large and undeniably important consequences for both the theory and application of deterrence. From a theoretical perspective, making the theory of criminal deterrence comport with differential weights for certainty and severity is no minor theoretical encumbrance, as Block and Heineke (1975) have shown (see also Witte, 1983). From an applied policy perspective, the idea that arresting deters more than convicting or upping the statutory penalty or imposed sentence makes a real difference. Differential weights have a role in telling governments how much of a return for crime reduction they can expect by putting their limited resources into apprehending and convicting criminals instead of punishing those who have been convicted more severely. Because it makes a world of difference, a serious discussion and investigation into the possibility of varying weights is past due.

In this paper, I ask whether any theoretical reason, while interesting in itself for individual level studies, are necessary to test the theory from a policy standpoint. While I am aware of the relevance of these questions for perceptual deterrence studies, aggregate studies need not occupy themselves with it. My purpose is to question the role that preferences, particularly risk, play in deterrent strategies. I believe that empirical findings supporting the differential weights may be artifactual in nature. This paper unfolds in three parts. First, I discuss how deterrence theory, from an applied policy standpoint, is encumbered through the explicit consideration of risk preferences. Next, I work through the algebra of 
the statistical formulations of deterrence models and demonstrate that the greater weight associated with certainty could well be an artifact of the model specification. Finally, I reanalyze data that appear to be consistent with the greater weight for certainty than severity argument and show that the evidence does not support that inference.

The Relative Importance of the Certainty and Severity of Punishment in Deterrence Theory and Application

If we simply listen to what deterrence theory says, the certainty and severity of punishment should have equal standing as deterrent factors because they operate in conjunction with one another to produce an expected cost of committing a crime. Yet, scholars have long insisted on the idea that rational individuals perceive the effects of the probabilities of arrest and conviction and the severity of punishment differently (Becker, 1968; Ehrlich, 1973; Eide, 1994; Decker and Kohfeld, 1990; Witte, 1983). There has been an unsettling two-fold doubt regarding the ambiguity of effects of the severity of punishment in deterrence theory going back to the eighteenth century. First, many empirical studies suggest and sometimes insist that severity does not have a deterrent effect; and, second, when severity is found to have an effect, it is not as strong as the effect of the certainty of punishment. Leaving the severity of punishment out of the theory, however, would "unbundle" the package (Mendes and McDonald, 2001). It is the idea that individuals perceive the deterrent components in conjunction that is key to comprehending deterrence theory.

The idea of the certainty and severity of punishment having different deterrent effects can be traced back to the Classical school of criminology. Recall that Beccaria (1965), Bentham (1789), and Montesquieu (1993) placed more emphasis on the certainty (and also on the celerity) of punishment than on the severity of punishment. The reason for this is based on their reaction to the cruelty of the Ancient Regime.

"Bentham and Beccaria thought that the certainty of punishment (of paying) is most important if the punishment (the price) is to deter. This stress on certainty is sometimes 
used to question the comparative effectiveness of severity. But Bentham and Beccaria meant to correct a contemporary situation: in the eighteenth century penalties were still extremely severe, but they were, perhaps for this reason, haphazardly applied and therefore uncertain.” (van den Haag, 1975, p. 115).

At the time, inflicted punishment was excessive compared to the crime committed. With this in mind, it is understandable that the Classicists' call for legal reform necessarily leaned toward the utilitarian notion of retribution or just deserts and away from any emphasis on the severity of punishment.

Since then, theorists and analysts alike have insisted on distinguishing the relative importance of the certainty and severity of punishment. When the social scientists of the $20^{\text {th }}$ century began investigating deterrence theory, this notion of differential importance between the two elements stuck. Sociologists and psychologists in the early to mid $20^{\text {th }}$ century began stressing the force of informal normative effects on individuals' perception of punishment.

\section{Preference for Risk and the Variation in the Deterrent Effects of the Certainty and Severity of}

\section{Punishment.}

Gary Becker (1968) is widely recognized for his seminal contribution to the study of crime. He is credited for having revived and updated the Utilitarian thought on crime by having elaborated the first formal model of deterrence theory with the mathematical contemplation of the preference for risk, thus providing economists and other social scientists with an "excuse" to find a variation in the relative importance of the certainty and severity of punishment. Specifically, he developed a theoretical economic approach to deterrence that Ehrlich (1973) later augmented to include both positive and negative incentive - the market model.

According to Becker's individual utility model: $\mathrm{O}=\mathrm{O}(\mathrm{p}, \mathrm{f}, \mathrm{u}), \mathrm{O}$, the average number of offenses, is a function of the average probability of being convicted (p), average punishment (f), and a vector of average socio-economic forces $(u)$. An increase in either the certainty or the severity of 
punishment will reduce the expected utility associated with the crime. But Becker's formulation of deterrence theory also states that the certainty and severity of punishment is conditional upon criminals' attitude towards risk. According to this addendum to deterrence theory, risk-acceptant individuals are deterred more by higher probabilities of arrest and conviction than by more severe punishment. On the theoretical side, Becker's objective in having come up with the formal solution to incorporate risk in deterrence theory was to corroborate a two-century-old "judicial hunch" that the deterrent force of the certainty and severity of punishment is conditional upon criminals' attitude towards risk (Shawcross, 1965),

“...a common generalization by persons with judicial experience is that a change in the probability has a greater effect on the number of offenses than a change in the punishment, although, as far as I can tell, none of the prominent theories shed any light on this relation." (Becker, 1968, p.176).

To accommodate this view, Becker added an attitudinal feature to his formal deterrence model—risk. The impact of certainty and severity on the crime rate differs depending on whether the criminal is risk neutral, risk averse, or risk acceptant. In other words, if the criminal is risk acceptant, then the certainty of punishment will be more influential in the decision of whether or not to commit crime than an increase in the severity of punishment; if a criminal is risk averse, then an increase in the severity of punishment will have a greater deterrent effect. Only if the criminal is risk neutral will certainty and severity have equal-standing deterrent effects.

According to Becker, then, the certainty and severity components are clearly identified as two equally relevant options available to reduce crime. Although deterrence theory in its most basic form (Becker, 1968) does not specify which of its elements should have a greater inhibiting effect on potential criminals, Becker was clearly concerned with the historical idea that the certainty of punishment carries a greater weight relative to the severity of punishment. On the empirical side, this discussion on the 
varying weights of the two components due to the role of risk has rested on this longstanding, unrefuted notion of the greater deterrent force of the certainty of punishment.

\section{Overburdening the Theory with Differential Weights of the Certainty and Severity of Punishment}

Deterrence theory is embodied in rational choice theory, and, as such, it focuses on the individual, meaning that the individual is the actor making the decision (von Neumann and Morgenstern, 1944; Luce and Raiffa, 1957; Lalman, Oppenheimer, and Swistak, 1993). Becker's model, recall, is an individual utility model. In the decisionmaking, there is an objective, factual component and a subjective component (Bernstein, 1996). Criminal decisionmaking is no different. The subjective component is the expected utility of committing a crime, which varies from individual to individual, utility being based on the value each individual attributes to a given good or activity. The objective component is the expected cost of committing a crime, which is the same for everyone. In the case of individual level deterrence studies, there is an objective component based on formal or legal sanctions and a subjective component based on informal or extra-legal sanctions. These legal and extra-legal sanctions combine to make up the expected utility of committing a crime. But in the case of aggregate level deterrence studies, there is

only an objective component to decisionmaking. This is because only at the individual level can attitudes and preferences be contemplated. The problem is that many nonindividual level empirical studies - aggregate level studies — supposedly provide support for Becker's risk solutions as if they test the individual causal relationships of the utility model.

On the theoretical side, since many decision models are based on individual behavior, the individual level of analysis is thought by many to be the most appropriate level of analysis. In analyzing policy initiatives, this is not the case; rather, the aggregate level is best level of analysis (Morton, 1999). There are "(...) propositions that are true in the aggregate but not in detail." (Schelling, 1957, p.49). When moving from the individual to the aggregate level, we lose information. This is necessarily so 
because the aggregate level cannot accommodate the infinite variation in individuals' preferences. This is why economic models do not deal with individual traits, such as preferences.

Policymakers operate at the aggregate level; they do not deal with individual aspects of deterrence, thus, for the purpose of policymaking, there is no need to incorporate individual or attitudinal features. At the policy stage, it is the aggregate that counts and not how each actor reacts within his/her constraints and with his/her preferences. It is one thing to test individual-level causal theories and another to test aggregate-level relationships (Schelling, 1957; Bartels and Brady, 1993). Models are useful in policymaking when they reflect many behaviors. Risk, operating as a preference, is therefore not a useful concept at the aggregate level. Deterrence theory at the aggregate level does not provide us with information on the effects of changes in tastes and preferences. These are assumed to be constant. Once we deal with ratio figures we are far from understanding the behavior and incentives that led to these figures. Thus, aggregate deterrence studies should be carried out without delving into attitudinal-related variations, namely risk.

"The simple mathematics of ratios and mixtures tells us something about what outcomes are logically possible, but tells us little about the behavior that leads to, or at least away from, particular outcomes (...) knowledge of individual behaviors will not by itself lead either to predictions of aggregate outcomes or to policies for affecting those outcomes. Attention must be paid to the macrophenomena that are the object of policy." (Shelling, 1978, pp. 142; 183).

On the empirical side, in aggregate level deterrence studies, attitudes, such as risk, are not directly analyzable because statistical models cannot and should not incorporate the psychological element of risk. As some authors (Chauncey, 1975; Gibbs, 1975; Tittle, 1980; Wilson and Herrnstein, 1985; von Hirsch et al., 1999) have argued in regard to other attitudinal features, such as the timing of punishment, these are not empirically nor statistically treated as a core component in aggregate level deterrence studies. Their place, as with the preference for risk, should lie at the micro-level. 
Despite the fact that risk is not directly incorporable in the statistical representation of deterrence at the aggregate level, the bulk of empirical deterrence findings lends support for Becker's theoretical solutions simply because the coefficients of the variables used to measure the certainty and severity of punishment are found to vary. Based on Becker's theoretical risk-dependent alternatives, the sole fact that certainty has been found to carry the greater effect has led empiricists to conclude that criminals are generally risk preferrers, thus suggesting to policymakers that certainty has a greater deterrent payoff than the severity of punishment.

Of course, I do not wish to imply that risk and other preferences do not play a role in deterrence theory. Although both individual level and aggregate level deterrence studies are important for the pursuit of knowledge on how individuals react or not to elements of deterrence, it is the expected cost of punishment that is central to governmental intervention to reduce criminal activity. I want to know if leaving psychological features to the side as individual level characteristics, as are tastes and preferences in economic models, would violate the essence of the theory at the aggregate level? If not, then there would be no theoretical reason to expect different magnitudes of the effects of certainty and severity of punishment.

On this basis, the role of attitudinal features in aggregate deterrence studies remains to be refuted. Does the reasoning criminal really consider getting caught, getting convicted, and the actual sentence he or she will have to pay or serve separately or rather as a combined effect? If not, then the consistency between the theory, including the provisions for risk, and the evidence of varying weights may simply constitute a methodological artifact of the way the components are measured. This means the certainty of punishment may not have a greater deterrent force after all. If so, the question then becomes: To what extent can we believe in what we have been told about the evidence of varying weights in deterrence theory? How can we trust the inferences that have been drawn from the findings in the empirical literature? This is of great importance for policymakers because empirical studies serve to help indicate where the resources of the criminal justice system should be channeled so as to arrive at the 
best, overall deterrent payoff. If studies indicate, perhaps incorrectly, a greater deterrent impact of the probability of arrest, then more resources will misguidedly be spent on catching criminals. If the psychological element of risk can be put aside theoretically, as is done empirically, one would be able to simplify an otherwise complex idea. And to do that, then one must question the variation in the coefficients of the deterrence components.

\section{Analysis of the Differential Effects of the Certainty and Severity Components of Punishment- Fact or Artifact?}

In this section, I present an algebraic and empirical analysis of the variation in the weights of the certainty and severity components of punishment. For this I use the log-linear model specification, given that it is the only model specification that respects the multiplicative relationship among the deterrence components, necessary in statistical representations of deterrence theory (see Mendes and McDonald (2001) for an exception and detailed demonstration of this argument).

The log-linear functional form explicitly allows for each of the deterrence components to have its own, separate deterrent effect on the crime rate, while preserving the interaction among them. Thus, the log-linear functional form can give us different impacts on the crime rate for the deterrence components; that is, it allows for a variation in each component's deterrent weight. Also, when estimating a log-linear model, arrests generally tend to get the most deterrent credit for having the greatest effect on the reduction of the crime rate. As would be expected, this has very real and serious implications for public authorities when it comes time to allocate scarce budgetary resources. More of these resources will likely go to hiring more police or providing them with better equipment. This means that the emphasis is placed on arresting criminals and raising the probability of arrest. But to what extent can we trust that the weights of the certainty and severity measures really do vary? The question that has been slowly unfolding is what if the empirical literature has inadvertently led policymakers in the wrong direction? Is it possible that this variation is merely an artifact of how the deterrent components of a statistical model designed to test deterrence theory are constructed? By algebraically 
decomposing the ratio measures of each of the deterrent variables, we may find that they are not as different as they appear to be. In fact, I find that the variation really is less than some like to stress. I also show that arrests may not always have the strongest net effect on the crime rate.

If I take a set of estimates of a log-linear model for robbery-estimates of a log-linear specification of the Decker and Kohfeld (1990) model (see Appendix 1)—and decompose the ratios, I am left with the logarithms of the numerators minus the logarithms of the denominators, as such:

$\ln ($ Crime Rate $)=\beta_{0}+\beta_{1}$ lnArrest Rate $+\beta_{2} \ln$ Conv $\mid$ Arr $+\beta_{3} \operatorname{lnTime}+\mu$. $\ln$ Off- lnpop $=\beta_{0}+\beta_{1} \ln$ Arrests $+\beta_{1} \ln$ Off $+\beta_{2} \operatorname{lnConv}+\beta_{2} \ln$ Arrests $+\beta_{3} \ln$ Time $+\beta_{3} \ln$ Conv $+\mu$.

As we can see, arrests and offenses share their effect on the dependent variable, that is, they have the same coefficient, $\beta_{1}{ }^{1}$ The same thing occurs with the probability of imprisonment and the severity measure. Convictions share its effect with arrests, through $\beta_{2}$, just as the number of months shares its deterrent impact with convictions, through $\beta_{3}$. Let us apply this logic and see how it affects the initial impact of the original estimates reported above. In the case of robbery:

$$
\begin{aligned}
& \ln (\text { Robbery Rate })=15.302+-1.871 \text { lnArrest Rate }+-.963 \ln \text { Conv } \mid \text { Arr }+-.676 \ln \text { Time }+\mu \\
& =15.302-1.871 \text { lnArrests }+1.871 \ln \text { Off }-.963 \ln \text { Conv }+.963 \ln \text { Arrests }-.676 \ln \text { Time }+.676 \ln \text { Conv }+\mu \\
& =15.302+(-1.871+.963) \text { lnArrests }+(-.963+.676) \ln \text { Conv }-.676 \ln \text { Time }+1.871 \ln O f f+\mu . \\
& =15.302-.924 \ln \text { Arrests }-.287 \ln \text { Conv }-.676 \ln \text { Time }+1.871 \ln \text { Off }+\mu .
\end{aligned}
$$

The algebra shows that the certainty of punishment variables has much smaller effects on the robbery crime rate. For instance, the arrest rate initially appears to have a weight of -1.871 , twice the magnitude of the probability of imprisonment and almost three times the magnitude of the severity of punishment variable. However, it appears that this arrest effect is "inflated" by way of offenses, that is, it benefits from having offenses in its denominator. The functional effect of the log of arrest rate is really the 
combined effect of the log of arrests and the log of offenses, so the deterrent effect of arrests is greater for having the added effect of offenses. The same is true of the probability of conviction, except in this case, the effect of conviction is the result of both convictions and arrests. The net effect for arrests really turns out to be .924 . That is half of the initial value, which is greater than the effect of the severity component. The net effect for convictions, -.287 , turns out to be less than a third of the overall effect of the probability of arrest and less than half of the functional effect of the severity of punishment.

In the case of burglary, the deflated effect of arrests, -..051, is even more extreme. It is less than one sixth of the effect of the severity of punishment and the net weight of convictions, -.157, is approximately half that of the severity of punishment.

$$
\begin{aligned}
& \text { In (Burglary Rate) } \\
& =9.289+-.518 \text { lnClear }+-.467 \ln \text { Conv } \mid \text { Arr }+-.310 \text { lnTime }+e . \\
& =9.289-.518 \text { lnArrests }+.518 \ln \text { Off }-.467 \text { lnConv }+.467 \text { lnArrests }-.310 \text { lnMonths }+.310 \ln \text { Conv }+e . \\
& =9.289+(-518+.467) \text { lnArrests }+(-.467+.310) \ln \text { Conv }-.310 \text { lnMonths }+.518 \ln \text { Off }+e . \\
& =9.289-.051 \text { lnArrests }-.157 \ln \text { Conv }-.310 \text { lnMonths }+.518 \ln \text { Off }+e .
\end{aligned}
$$

In the end, we see that it is offenses that has the greatest weight. Any deterrent component having offenses in it benefits from its force. This is clear in the case of arrests, for it no longer has as substantial a deterrent weight as before, and in the case of burglary it evens falls behind the impact of convictions and the number of months served in prison. For robbery, the arrests weight went from 1.871 to -.924 and for burglary, it went from -.518 to -.051 . The functional effect of convictions dropped from -.963 to -.287 for robbery and from -.467 to -.157 . Curiously, the only coefficient that remains intact when it is decomposed is the severity measure, median time served; it is still -.676 for robbery and -.310 in the case of burglary after I remove convictions from its denominator. It is also worth noticing that it is now the measure with the greatest weight in the case of burglary.

So we can see that how we measure the certainty and the severity components in a statistical deterrence model has important implicit implications and the resulting coefficients should be interpreted 
with this in mind. Just because the log-linear estimates show arrests having a greater effect than the conviction or the severity of punishment does not necessarily mean that it does or at least that it may not be as great as it appears to be.

I can take the argument one step further from the algebra to the empirics. My objective is to see what happens to the deterrent components' functional effects when I make some incremental adjustments to the model and when I mathematically decompose and estimate the ratio terms on the certainty and severity variables.

In Table 1, I present findings for two different versions of the log-linear functional form of the Decker and Kohfeld (1990) model. The results are based on the Thomas Pogue data set Deterrent Effects of Imprisonment and Arrests in the United States 1960-1970 (Pogue, 1983; ICPSR File 7973). The choice of this model, and, consequently, the data set used, is based the fact that the model was estimated in a published empirical analysis using aggregate level state-wide data with all three deterrence components. Surprisingly, aggregate level state-wide data are uncommon. There are many individual level data available, however, for the purposes of this paper, these, of course, are not suitable. Critics may question the use of data going back so far in time, but the argument I am making is not sensitive to time. Therefore, the choice of data, so as long as it is aggregate level data, makes no difference.

Appendix 2 provides detailed information on the nature of the data, namely descriptive statistics and variable definitions. The data are 1970 data and cover 32 States. Some States were excluded due to the lack of available data: Alabama, Arkansas, Florida, Indiana, Iowa, Louisiana, Michigan, Nebraska, New Jersey, North Carolina, Oregon, Pennsylvania, Rhode Island, Texas, Virginia, and Wisconsin. Alaska and Hawaii were excluded at the outset. Vermont is dropped from the robbery analyses for the same reason. In 1970, there were typically 100 robberies and approximately nine times as many burglaries for every 100,000 persons. The average clearance rate was also substantially higher for robbery than for burglary-34\% as compared to $20 \%$ for burglary. The probability of conviction was 
higher for robbery than for burglary. About one third of the robberies were cleared by arrests and approximately one-fifth of those arrested for robbery were convicted. In the case of burglary, about $20 \%$ of burglaries were cleared, and of those arrested only $5 \%$ were convicted. As for the severity variables, we can see that those convicted of robbery were serving longer sentences than those convicted of burglary, as the median time served was about 34 months for robbery and 20 months for burglary.

As discussed in the analysis above, because the log-linear model allows for variation in functional weights, I examine the construction of the model and the measures used in the model. I test the strength of the deterrent effects by decomposing the ratio terms on the right-hand side like so:

$\ln ($ Crime Rate $)=\beta_{0}+\beta_{1}$ lnArrests $+\beta_{2}$ lnConvictions $+\beta_{3}$ lnMonthsServed $+\beta_{4}$ InOffenses $+\beta_{5}$ lnNonwhite $+\beta_{6}$

$$
\text { lnUnemploy }+\mu \text {. }
$$

The first column of each crime type shows the results of the estimation of the log-linear version of the Decker and Kohfeld model. The second column of the each crime type shows the estimates of the decomposed version of the same model. These estimates reveal a deterrent effect for the number of months served for both robbery and burglary but no deterrent effect of the arrests, nor convictions variables for either crime. This tells us that without offenses built into the arrest term, the arrests variable does not produce a deterrent effect.

[Table 1 about here]

\section{Discussion}

These findings have important practical implications from a policy standpoint. Because the existing literature has typically found the certainty and severity components to vary, it has led policymakers to believe that a rational approach to deterring crime is best achieved through the certainty component by investing more in apprehending and convicting criminals rather than increasing the severity of punishment by lengthening criminal sentences. The results are especially revealing in the case of the probability of arrest because it is generally considered to be the best policy option for 
reducing crime. Naturally, there are tradeoffs involved in the allocation of criminal justice resources. It makes a difference to whether more resources are channelled to the police and prosecutors than to the prison system because both options have very different costs associated with them. Given the scarcity of resources, increasing the probability of arrest necessarily implies a decrease in the probability of conviction or the effective severity of punishment. This is because more criminals are being apprehended but no more resources are being made available to prosecutors, courts, and prisons, unless the whole criminal justice budget increases. Fewer criminals will be convicted and fewer criminals will effectively serve a sentence. Likewise, there would be a tradeoff if instead the probability of conviction were increased or the length of sentences were increased because less resources would be available to the prison system to hold the additional incoming convicted felons and to the police to catch criminals in the first case and to the police and prosecutors in the second. These implications show that it matters where the criminal justice system allocates its resources. So it matters that the empirical findings be robust enough to direct the criminal system on where resources should be invested.

It is necessary to underscore that I am not advocating that legislators should divert attention from the police and instead focus on increasing the severity of punishment. Rather, my argument is that no one of the deterrence components should be more important than another where deterrence strategies are concerned. As I see it, there are two extremities with respect to punishment: 1) those who are not particularly concerned with severity of punishment; and 2) those who overly concerned with it. In my mind, the former position defeats the point of deterrence theory. Not being concerned with severity means leaving the theory incomplete. On the other hand, the latter position lays the burden of deterrence theory on the shoulders of those who get convicted because extremely severe punishment raises the expected cost of punishment at the expense of the imprisoned. In this case, although deterrence theory is kept intact, it is done so by tipping the deterrence scale in favor of the severity of punishment component. This raises moral issues of extreme punishment by overlooking the means in order to achieve the ends. A balance of both components would achieve the best overall result for deterrence 
policy strategies. What is necessary is that criminals effectively serve their punishment. That means they be caught, convicted, and serve their due sentence. And this only implies that a balance be struck between resource efficiency and the moral question of punishment.

\section{Conclusion}

For over two centuries, scholars and law practitioners have insisted that the certainty of punishment is more important than the severity of punishment when it comes to criminal deterrence. To accommodate this traditional view, Becker extended the essence of deterrence theory by including an attitudinal feature that accounts for a variation in the importance that potential criminals attribute to the deterrent elements. This attitudinal feature is risk. Of course his model is an individual choice model, thus "the key feature is the notion of utility" (Witte and Witt, forthcoming). Policymakers work at the aggregate level, which means that they do not deal with expected utility, but rather focus solely on the expected cost of punishment. This means that risk does not have to be considered if we are talking about aggregate deterrence studies. The essence of deterrence theory would not change if we did not consider these theoretical variations in deterrence theory. If so, then there is nothing in deterrence theory that should lead us to expect different effects for each deterrent component. That is, we should not theoretically expect the certainty of punishment to have a greater weight than the severity of punishment.

Most of empirical deterrence findings since Becker lends support for his risk solutions, despite the fact that they are not analyzable at the aggregate level. These findings have led us to believe that certainty and severity of punishment have distinct weights. It is this variation in deterrent effects that has made it possible to suggest that criminals are more risk acceptant, thus suggesting to policymakers that certainty has a greater deterrent payoff than the severity of punishment.

In this paper, I question the need to overburden deterrence theory from a policy stance by incorporating risk. Risk is an attitude, and attitudes are individual attributes. As such, they cannot be tested at the aggregate level. If I am right in questioning the role of risk in the basic deterrence theory, 
then how does one deal with the empirical studies that have found varying weights? The results of both an algebraic manipulation and statistical analysis of the log-linear model—which respects the three-way multiplicative relationship among the deterrence components, a necessary feature of any statistical representation of deterrence theory - lend support for my hypothesis. After having algebraically and empirically explored the log-linear model, I reach an important conclusion: the functional effects or weights of the probabilities of arrest and conviction, and the severity of punishment do not really vary as much as deterrence scholars would lead us to believe. Potential criminals mentally combine the three deterrence components, regardless of whether they are risk neutral, averse, or acceptant. If the weights really do not vary, then, according to Becker's risk solutions, criminals are really risk neutral. This being the case, it is entirely plausible to doubt if it is necessary to tax deterrence theory with the consideration of the psychological element of risk where policymaking is concerned.

\section{References}

Antunes, George \& A. Lee Hunt. (1973). The Deterrent Impact of Criminal Sanctions: Some Implications for Criminal Justice Policy. Journal of Urban Law, 51 (2) 145-61.

Bartels, Larry M. \& Henry E. Brady. (1993). The State of Quantitative Political Methodology. In Political Science The State of the Discipline II, Ada W. Finifer, ed.. Washington,DC: APSA.

Beccaria, Cesare. (1965). Des Délits et des Peines. Genève: Libraire Droz.

Becker, Gary S. (1968). Crime and Punishment: An Economic Approach. Journal of Political Economy, $78,169-217$.

Bentham, Jeremy. (1789). Uma Introdução aos Princípios do Moral e da Legislação. S. Paulo: Abril. Bernstein, Peter L. (1996). Against the Gods: The Remarkable Story of Risk. New York: Wiley. Block, M. K. \& J. M. Heineke. (1975). A Labor Theoretic Analysis of the Criminal Choice. American Economic Review, 65 (3), 314-25. 
Chambliss, William. (1966). The Deterrent Influence of Punishment. Crime and Delinquency, 12 (Jan.), $70-5$.

Chauncey, Robert. (1975).Deterrence: Certainty, Severity, and Skyjacking. Criminology, 12 (4), 447-73.

Decker, Scott \& Carol W. Kohfeld. (1990). Certainty, Severity, and the Probability of Crime: A Logistic Analysis. Policy Studies Journal, 19 (1), 2-21.

Ehrlich, Isaac. (1973). Participation in Illegitimate Activities: A Theoretical and Empirical Investigation. Journal of Political Economy, 81 (3), 521-65.

Eide, Erling. (1994). Economics of Crime: Deterrence and the Rational Offender. Amsterdam: North Holland.

Gibbs, Jack P. (1968). Crime, Punishment, and Deterrence. Southwestern Social Science Quarterly, 48 (4), 515-30.

Gibbs, Jack P. (1975). Crime, Punishment, and Deterrence. New York, NY: Elsevier.

Grasmick, Harold G. \& George J. Bryjak. (1980). The Deterrent Effect of Perceived Severity of Punishment. Social Forces, 59 (2), 471-91.

Gray, Louis N. \& J. David Martin. (1969). Punishment and Deterrence: Another Analysis of Gibbs' Data. Social Science Quarterly, 50 (Sept.), 389-95.

Lalman, David, Joe Oppenheimer, \& Piotr Swistak. (1993). Formal Rational Choice Theory: A Cumulative Science of Politics. In Political Science The State of the Discipline II, Ada W. Finifer, ed.. Washington,DC: APSA.

Logan, Charles H. (1972). General Deterrent Effects of Imprisonment. Social Forces, 51 (September), 64-73.

Luce, R. Duncan \& Howard Rafia.(1957). Games and Decisions. New York; NY: Dover. Mendes, Silvia M. \& Michael D. McDonald. (2001). Putting Severity of Punishment Back in the Deterrence Package. Policy Studies Journal, 29 (4), 588-610. 
Morton, Rebecca. B. (1999). A Guide to the Empirical Analysis of Formal Models in Political Science. Cambridge, UK: Cambridge University Press.

Montesquieu, Charles de Secondat Baron de. (1993). O Espírito das Leis, Livro VI. S. Paulo: Martins Flores.

Pogue, Thomas F. (1983). The Crime Prevention Effects of Arrests and Imprisonment: Evidence From Multiple Cross-Section Analyses, ICPSR Study \# 7973. Ann Arbor, MA: National Institute of Justice.

Shawcross, Lord. (1965). Crime Does Pay Because We Do Not Back Up the Police. New York Times Magazine (June 13).

Shelling, Thomas C. (1978). Micromotives and Macrobehavior. New York, NY: W.W.Norton.

Sjoquist, David. (1973). Property Crime and Economic Behavior: Some Empirical Results.” American Economic Review, 63 (3), 439-46.

Tittle, Charles R. (1969). Crime Rates and Legal Sanctions. Social Problems, 16 (4), 409-23.

Tittle, Charles R. (1980). Sanctions and Social Deviance: The Question of Deterrence. New York, NY: Praeger.

Tullock, Gordon. (1974). Does Punishment Deter Crime? The Public Interest, 36 (Summer), 103-11. van den Haag, Ernest. (1975). Punishing Criminals: Concerning a Very Old and Painful Question. New York, NY: Basic Books.

von Hirsch, Andrew, Anthony E. Bottoms, Elizabeth Burney, \& P-O Wickstrom. (1999). Criminal Deterrence and Sentence Severity. Oxford, UK: Hart.

von Neumann, John \& Oskar Morgenstern. (1944). Theory of Games and Economic Behavior. Princeton, NJ: Princeton University Press.

Wilson, James Q. \& Richard J. Herrnstein. (1985). Crime and Human Nature. New York: Simon and Schuster. 
Witte, Ann Dryden. (1983). Economic Theories. In Encyclopedia of Crime and Justice Vol 1, Sanford H. Kalish, ed., New York: Free Press.

Witte, Ann Dryden \& Robert Witt. Crime Causation: Economic Theories. Forthcoming Encyclopedia of Crime Justice. New York: Free Press. 
Table 1: Results of the Decomposition of the Deterrence Variables in a Log-Linear Model for Robbery and Burglary in 1970

\begin{tabular}{|c|c|c|c|c|}
\hline & Robbery & & Burglary & \\
\hline Variable & $\begin{array}{l}\text { Log-Linear } \\
\text { Model }\end{array}$ & $\begin{array}{c}\text { Decomp. } \\
\text { Right-hand } \\
\text { Side }\end{array}$ & $\begin{array}{c}\text { Log-Linear } \\
\text { Model }\end{array}$ & $\begin{array}{c}\text { Decomp. } \\
\text { Right-hand } \\
\text { Side }\end{array}$ \\
\hline Intercept & $\begin{array}{c}15.302^{*} \\
(2.351)\end{array}$ & $\begin{array}{r}.883 \\
(2.028)\end{array}$ & $\begin{array}{l}9.289^{*} \\
(1.265)\end{array}$ & $\begin{array}{c}5.877^{*} \\
(1.452)\end{array}$ \\
\hline Clear & $\begin{array}{r}-1.871^{*} \\
(.536)\end{array}$ & & $\begin{array}{l}-.518^{*} \\
(.315)\end{array}$ & \\
\hline Conv| Arr & $\begin{array}{l}-.963^{*} \\
(.205)\end{array}$ & & $\begin{array}{l}-.467^{*} \\
(.087)\end{array}$ & \\
\hline Time & $\begin{array}{c}-0.676^{*} \\
(.279)\end{array}$ & & $\begin{array}{l}-.310^{*} \\
(.140)\end{array}$ & \\
\hline Nonwhite & $\begin{array}{l}.436^{*} \\
(.126)\end{array}$ & $\begin{array}{l}.188^{*} \\
(.093)\end{array}$ & $\begin{array}{l}.212^{*} \\
(.062)\end{array}$ & $\begin{array}{l}.134^{*} \\
(.077)\end{array}$ \\
\hline Unemploy & $\begin{array}{l}-.963^{*} \\
(.205)\end{array}$ & $\begin{array}{l}-.681 \\
(.380)\end{array}$ & $\begin{array}{r}.117 \\
(.284)\end{array}$ & $\begin{array}{r}.205 \\
(.280)\end{array}$ \\
\hline Arrests & & $\begin{array}{r}.138 \\
(.441)\end{array}$ & & $\begin{array}{r}.019 \\
(.324)\end{array}$ \\
\hline Conv & & $\begin{array}{c}.074 \\
(.190)\end{array}$ & & $\begin{array}{c}.074 \\
(.140)\end{array}$ \\
\hline Months & & $\begin{array}{l}-.401 * \\
(.189)\end{array}$ & & $\begin{array}{c}-.280^{*} \\
(.137)\end{array}$ \\
\hline$\overline{\text { Offn }}$ & & $\begin{array}{l}.708^{*} \\
(.404)\end{array}$ & & $\begin{array}{r}.438 \\
(.309)\end{array}$ \\
\hline $\mathrm{N}$ & 31 & 31 & 32 & 32 \\
\hline$\overline{\mathrm{R}^{2}}$ & .742 & 893 & .596 & .634 \\
\hline Adj. $R^{2}$ & .690 & .867 & .518 & .546 \\
\hline $\mathrm{S}_{\mathrm{e}}$ & .585 & .383 & .307 & .297 \\
\hline
\end{tabular}

Note: The values in parentheses are the standard errors of the coefficients.

*Significant at the .05 level, one-tail test. 


\section{Appendix 1: Results of a Log-Linear Model for Robbery and Burglary, in 1970}

\begin{tabular}{|c|c|c|}
\hline & Robbery & Burglary \\
\hline Variable & $\begin{array}{c}\text { Log-linear } \\
\text { Model }\end{array}$ & $\begin{array}{l}\text { Log-linear } \\
\text { Model }\end{array}$ \\
\hline Intercept & $\begin{array}{r}15.302 \\
(2.351)^{*}\end{array}$ & $\begin{array}{r}9.289 \\
(1.265)^{*}\end{array}$ \\
\hline Clear & $\begin{array}{l}-1.871 \\
(.536)^{*}\end{array}$ & $\begin{array}{r}-.518 \\
(.315) \\
\end{array}$ \\
\hline Conv $\mid$ Arr & $\begin{array}{r}-.963 \\
(.205)^{*}\end{array}$ & $\begin{array}{r}-.467 \\
(.087)^{*}\end{array}$ \\
\hline Time & $\begin{array}{l}-0.676 \\
(.279)^{*}\end{array}$ & $\begin{array}{r}-.310 \\
(.140)^{*}\end{array}$ \\
\hline Nonwhite & $\begin{array}{r}.436 \\
(.126)^{*}\end{array}$ & $\begin{array}{r}.212 \\
(.062)^{*}\end{array}$ \\
\hline Unemploy & $\begin{array}{r}-.963 \\
(.205)^{*}\end{array}$ & $\begin{array}{r}.117 \\
(.284)\end{array}$ \\
\hline $\mathrm{N}$ & 31 & 32 \\
\hline$\overline{\mathrm{R}^{2}}$ & .742 & .596 \\
\hline Adjusted $\mathrm{R}^{2}$ & .690 & .518 \\
\hline $\mathrm{S}_{\mathrm{e}}$ & .585 & .307 \\
\hline
\end{tabular}

Notes: 1) Estimates are based on a log-linear model transformation of the Decker and Kohfeld (1990) model, estimated using the Pogue (1983) data:

$$
\ln (\text { C rate } / 1-\text { C rate })=\beta_{0}+\beta_{1} \text { Clear }+\beta_{2} \text { Conv } \mid \text { Off }+\beta_{3} \text { Time }+\beta_{2} \text { Nonwhite }+\beta_{3} \text { Unemploy }+\mu \text {. }
$$

2.) The values in parentheses are the standard errors of the coefficients.

*Significant at the .05 level, one-tail test. 


\section{Appendix 2: Variables, Definitions, and Descriptive Statistics}

\begin{tabular}{|c|c|c|c|c|c|}
\hline Variable & Variable Definition & Mean & Std. Dev. & Minimum & Maximum \\
\hline \multicolumn{6}{|l|}{ Robbery } \\
\hline Crime Rate & $\begin{array}{l}\text { The number of robberies per } 100,000 \text { persons known to } \\
\text { police in } 1970\end{array}$ & 100.059 & 99.872 & 6.400 & 442.100 \\
\hline Clear & $\begin{array}{l}\text { The percentage of reported robberies cleared by arrest in } \\
1970\end{array}$ & 33.512 & 8.037 & 19.000 & 50.600 \\
\hline Conv|Arr & $\begin{array}{l}\text { The percentage of convictions given arrests for robbery in } \\
1970\end{array}$ & 18.885 & 11.496 & 3.852 & 55.488 \\
\hline Time & $\begin{array}{l}\text { The median time served in months before first release by } \\
\text { persons committed to state prisons for robbery and } \\
\text { released in } 1970\end{array}$ & 34.273 & 19.786 & 13.000 & 120.000 \\
\hline \multicolumn{6}{|l|}{ Burglary } \\
\hline Crime Rate & $\begin{array}{l}\text { The number of burglaries per } 100,000 \text { persons known to } \\
\text { police in } 1970\end{array}$ & 914.194 & 374.134 & 286.200 & 1751.500 \\
\hline Clear & $\begin{array}{l}\text { The percentage of reported burglaries cleared by arrest in } \\
1970\end{array}$ & 19.746 & 3.767 & 12.700 & 28.200 \\
\hline Conv|Arr & $\begin{array}{l}\text { The percentage of convictions given arrests for burglary } \\
\text { in } 1970\end{array}$ & 5.452 & 3.344 & .807 & 14.596 \\
\hline Time & $\begin{array}{l}\text { The median time served in months before first release by } \\
\text { persons committed to state prisons for burglary and } \\
\text { released in } 1970\end{array}$ & 20.907 & 17.664 & 7.500 & 112.286 \\
\hline \multicolumn{6}{|c|}{ Socioeconomic } \\
\hline Nonwhite & $\begin{array}{l}\text { Percentage of the total state population that is nonwhite in } \\
1970\end{array}$ & 9.584 & 8.603 & .707 & 37.052 \\
\hline Unemploy & The percentage of labor force unemployed in 1970 & 4.494 & 1.005 & 3.200 & 7.900 \\
\hline
\end{tabular}

\footnotetext{
${ }^{1}$ As early as the 70s, authors such as Jack Gibbs, Charles Tittle, and Charles Logan had already discussed the inflation of the certainty estimates given the common term among the certainty variables and the dependent variable, the crime rate.
} 